\title{
Role of integrin-linked kinase in static compressive stress-induced autophagy via phosphatidylinositol 3 kinase in human periodontal ligament cells
}

\author{
RUI ZOU ${ }^{1-3^{*}}$, SHIYANG WU ${ }^{1-3^{*}}$, YIJIE WANG ${ }^{1-3}$, XUEPING KANG ${ }^{1-3}$, SHUYANG ZHAO ${ }^{3,4}$, \\ HAOYU SHI ${ }^{3,4}$, DANQING ZHENG ${ }^{1-3}$, BEI GAO ${ }^{1-3}$, SHUYU MA ${ }^{1-3}$, LIN NIU $^{1-3}$ and YUNAN GAO ${ }^{1-3}$ \\ ${ }^{1}$ Key Laboratory of Shaanxi Province for Craniofacial Precision Medicine Research, College of Stomatology, \\ Xi'an Jiaotong University; ${ }^{2}$ Clinical Research Centre of Shaanxi Province for Dental and Maxillofacial Diseases, \\ College of Stomatology, Xi'an Jiaotong University; ${ }^{3}$ College of Stomatology, ${ }^{4}$ Health Science Centre, \\ Xi'an Jiaotong University, Xi'an, Shaanxi 710004, P.R. China
}

Received December 16, 2020; Accepted May 27, 2021

DOI: $10.3892 / \mathrm{ijmm} .2021 .5000$

\begin{abstract}
Orthodontic tooth movement (OTM) is achieved by using mechanical stimuli, which lead to the remodeling of periodontal tissues. Previous findings have demonstrated that autophagy may be one of the cell responses to mechanical stress. As a key structure in the integrin pathway, integrin linked-kinase (ILK) may play a role in the transmission of these mechanical signals. In addition, ILK is an important upstream molecule that regulates autophagy, under the influence of phosphatidylinositol 3 kinase (PI3K). Therefore, exploring the effect of mechanical stress on autophagy and the associated role of ILK/PI3K is of utmost significance to
\end{abstract}

Correspondence to: Professor Lin Niu or Dr Yunan Gao, Key Laboratory of Shaanxi Province for Craniofacial Precision Medicine Research, College of Stomatology, Xi'an Jiaotong University, 98 Xiwu Road, Xi'an, Shaanxi 710004, P.R. China

E-mail: niulin@mail.xjtu.edu.cn

E-mail: 55495131@qq.com

*Contributed equally

Abbreviations: 2D, two-dimensional; 3D, three-dimensional; AKT, kinase B; CCK-8, cell counting kit-8; DAPI, 4-6-diamidino2-phenylindole; DGL, D-(+)-Glucono-1,5-lactone; DMEM, Dulbecco's modified Eagle's medium; DMSO, dimethyl sulfoxide; ECM, extracellular matrix; FBS, fetal bovine serum; GAPDH, glyceraldehyde-3-phosphate dehydrogenase; hPDLC, human periodontal ligament cell; ILK, integrin linked-kinase; mTOR, mammalian target of rapamycin; OA, osteoarthritis; OD, optical density; OTM, orthodontic tooth movement; PBS, phosphate-buffered saline; PDL, periodontal ligament; PI3K, phosphatidylinositol 3 kinase; PIP3, phosphatidylinositol $(3,4,5)$ triphosphate; RT-qPCR, reverse transcription-quantitative polymerase chain reaction; SEM, standard error of the mean

Key words: static compressive stress, autophagy, human periodontal ligament cells, integrin-linked kinase, phosphatidylinositol 3 kinase understanding the mechanism behind OTM. In the present study, human periodontal ligament cells (hPDLCs) were embedded into a collagen-alginate complex hydrogel for three-dimensional (3D) culturing. Static compressive stress $\left(2.5 \mathrm{~g} / \mathrm{cm}^{2}\right)$ was loaded using the uniform weight method for $5,15,30$, and $60 \mathrm{~min}$. The autophagy of hPDLCs was detected by the expression of Beclin-1 (BECN1) and ATG-5 using RT-qPCR and LC3, respectively, using immunofluorescence. The results showed that the level of autophagy and gene expression of $I L K$ increased significantly under static compressive stress. In ILK-silenced cells, static compressive stress could also upregulate ILK expression and increase the levels of autophagy. After PI3K inhibition, the increase in the autophagy level and the upregulation of $I L K$ expression disappeared. These findings suggest that static compressive stress can induce autophagy in hPDLCs in a rapid, transient process, regulated by ILK and PI3K. Moreover, this static stress can upregulate $I L K$ expression in a PI3K-dependent manner.

\section{Introduction}

The cell microenvironment, including mechanical forces, has emerged as a key determinant of cell behavior and function. The physiological function of cells in vivo is closely related to the various types of mechanical forces present. The periodontal ligament (PDL) is the supporting tissue that connects the teeth to the alveolar bone in the oral cavity. As a result, the PDL is frequently subjected to mechanical stimulation owing to mastication, biting, or orthodontic forces. Orthodontic tooth movement (OTM) causes periodontal tissue remodeling, which involves complex biochemical reactions and cellular signal transduction pathways (1). Human periodontal ligament cells (hPDLCs) are the main cells residing in the PDL that participate in the restoration and remodeling of periodontal tissue. Over the past two decades, various forces such as fluid shear, centrifugal force, and tension have been applied to hPDLCs to explore the effect of orthodontic forces on periodontal tissues (2-4). However, the cells used in those studies 
were often cultured in two dimensions, which is inconsistent with the dynamic three-dimensional microenvironment found in vivo (5). Thus, it is crucial to find a suitable mechanical stress model to explore the effects of cellular mechanics on the regulation of cell fate.

Previous studies have found that mechanical stress can regulate a variety of cellular behaviors, such as cell proliferation, apoptosis, and differentiation $(6,7)$. However, there are insufficient data on the process of autophagy. Autophagy is a process during which a cell degrades its damaged organelles and proteins using lysosomes $(8,9)$. It is an important mechanism for maintaining intracellular homeostasis and integrity. As a dominant catabolic mechanism, autophagy is involved in the physiological and pathological processes of cells (10). Increasing evidence suggests that there is a close relationship between autophagy and mechanical stress. King et al (11) found that mammalian cells can respond to mechanical stress by rapidly inducing the formation of autophagosomes. This indicates that autophagy can be activated when cells adapt to mechanical stress. Ma et al (12) suggested that autophagy may be a key response by nucleus pulposus cells resisting mechanical overload. Mechanical stress triggers autophagy and excessive autophagy leads to cell death. This process involves complex mechanical signal transduction pathways.

The extracellular matrix-integrin-cytoskeleton has been reported to be an important mechanical signal transduction pathway $(13,14)$ Integrin-linked kinase (ILK), the cytoplasmic domain of $\beta 1$ integrin, performs a central role in cell growth, survival, and differentiation (15-17). It can promote actin rearrangement and participate in the maturation of focal adhesions (15). A lack of ILK results in less adhesion of fibroblasts to the ECM, prevents defective cell extension, and delays the formation of adhesion sites (18). In addition, ILK can also exhibit kinase activity and can activate the kinase B (AKT)/mammalian target of rapamycin (mTOR), a key regulatory pathway of autophagy, with the assistance of phosphatidylinositol 3 kinase (PI3K) $(19,20)$. Sosa et al (21) proposed that hyperphosphatemia may activate mTOR and reduce autophagy in myoblasts through ILK activation. In recent studies it was confirmed that ILK is a key molecule involved in the effect of mechanical stress on the proliferation, apoptosis, and differentiation of hPDLCs $(22,23)$. Therefore, ILK/PI3K may be important connecting molecules that transmit mechanical signals to downstream pathways, thereby mediating the effect of mechanical forces on autophagy in hPDLCs.

In the present study, a collagen-alginate composite hydrogel was used to create a $3 \mathrm{D}$ cell culture in vitro to simulate the periodontal microenvironment. The uniform weight method (24) was used to generate unidirectional static compressive stress that is similar to orthodontic forces, to explore the effect of mechanical stress on autophagy in hPDLCs. Models of ILK silencing and PI3K-specific inhibitory hPDLCs were also established to verify the role of ILK/PI3K in this process. A schematic diagram of the methods for developing this study is presented in Fig. 1. The aim of the present study was to provide insight into exploring the molecular mechanisms of periodontal remodeling and OTM.

\section{Materials and methods}

Cell isolation and culture. The culture and usage of hPDLCs in the present study were approved by the Ethics Committee of Xi'an Jiaotong University (no. 2019-1282), and informed consent was obtained from all the patients. hPDLCs were isolated from premolar teeth, which were extracted for orthodontic reasons, from teenagers between the ages of 12 and 15 years. After rinsing the teeth with phosphate-buffered saline (PBS) supplemented with $100 \mathrm{U} / \mathrm{ml}$ penicillin and $100 \mathrm{U} / \mathrm{ml}$ streptomycin, the periodontal tissue was gently collected from the middle of the root. The tissue was then digested with type I collagenase (Sigma-Aldrich; Merck KGaA) and dispase (Beijing Solarbio Science \& Technology Co., Ltd.) at $37^{\circ} \mathrm{C}$, for $40 \mathrm{~min}$. The cells were then re-suspended in Dulbecco's modified Eagle's medium (DMEM; Gibco; Thermo Fisher Scientific, Inc.) culture medium containing $10 \%$ fetal bovine serum (FBS; Gibco; Thermo Fisher Scientific, Inc.). Cells at 3-5 passages were selected for this experiment (25). The verification methods are described in the immunofluorescence staining section below. After blocking using 5\% bull serum albumin (Wuhan Boster Biological Technology, Ltd.), hPDLCs were subjected to immunofluorescence with primary antibodies to vimentin and cytokeratin (1:300, BM0135 and BM0030; Wuhan Boster Biological Technology, Ltd.). Cells used in the present study were derived from one individual. The results of characterization of the hPDLCs are presented in Fig. S1.

Construction of the $3 D$ static stress loading model for hPDLCs using collagen-alginate hydrogel. The dissolved type I collagen solution (extracted from 8-week-old female Sprague-Dawley rats weighing 280-320 g without any specific treatment), DMEM (Gibco; Thermo Fisher Scientific, Inc.), sodium alginate solution (Sigma-Aldrich; Merck KGaA), D-(+)-glucono-1,5-lactone (DGL, Thermo Fisher Scientific, Inc.), $\mathrm{CaSO}_{4}$ (Tianjin Kemiou Chemical Reagent Co. Ltd.) and $\mathrm{NaOH}$ (Tianjin Tianli Chemical Reagent Co. Ltd.) solution were mixed in a predetermined order and proportion. Next, the hPDLC suspension obtained after digestion with trypsin (Beijing Solarbio Science \& Technology Co., Ltd.) was added. The mixed solution was added to the pre-designed mold and placed in an incubator $\left(37^{\circ} \mathrm{C}\right)$ for $1 \mathrm{~h}$. The mold was then removed, the formed hydrogel was placed into a $6 \mathrm{~mm}$ petri dish, and $3 \mathrm{ml}$ of DMEM containing 10\% FBS was placed over the gel; it was then placed back to incubator $\left(37^{\circ} \mathrm{C}\right)$. The culture medium was changed every other day (Fig. 2A) and static stress was loaded after $72 \mathrm{~h}$.

Cell counting kit-8 (CCK-8) assay. The cells were mixed with liquid hydrogel or seeded in DMEM, containing various concentrations $(0,25,50$ and $100 \mathrm{mmol} / \mathrm{l})$ of inhibitors (LY294002, Echelon Biosciences), and transferred to a 96-well culture plate. A set of five wells in each group were used as controls. After the cells were cultured for $12 \mathrm{~h}$ at $37^{\circ} \mathrm{C}$ in a $5 \% \mathrm{CO}_{2}$ incubator, $10 \mu \mathrm{l}$ of CCK-8 solution (Beijing Solarbio Science \& Technology Co., Ltd.) was added to each well in the dark every $12 \mathrm{~h}$. A microplate reader (Multiskan FC; Thermo Fisher Scientific, Inc.) was used to measure the optical density (OD) value of each well at a wavelength of $450 \mathrm{~nm}$, at 0,12 , 24,48 and $72 \mathrm{~h}$. 


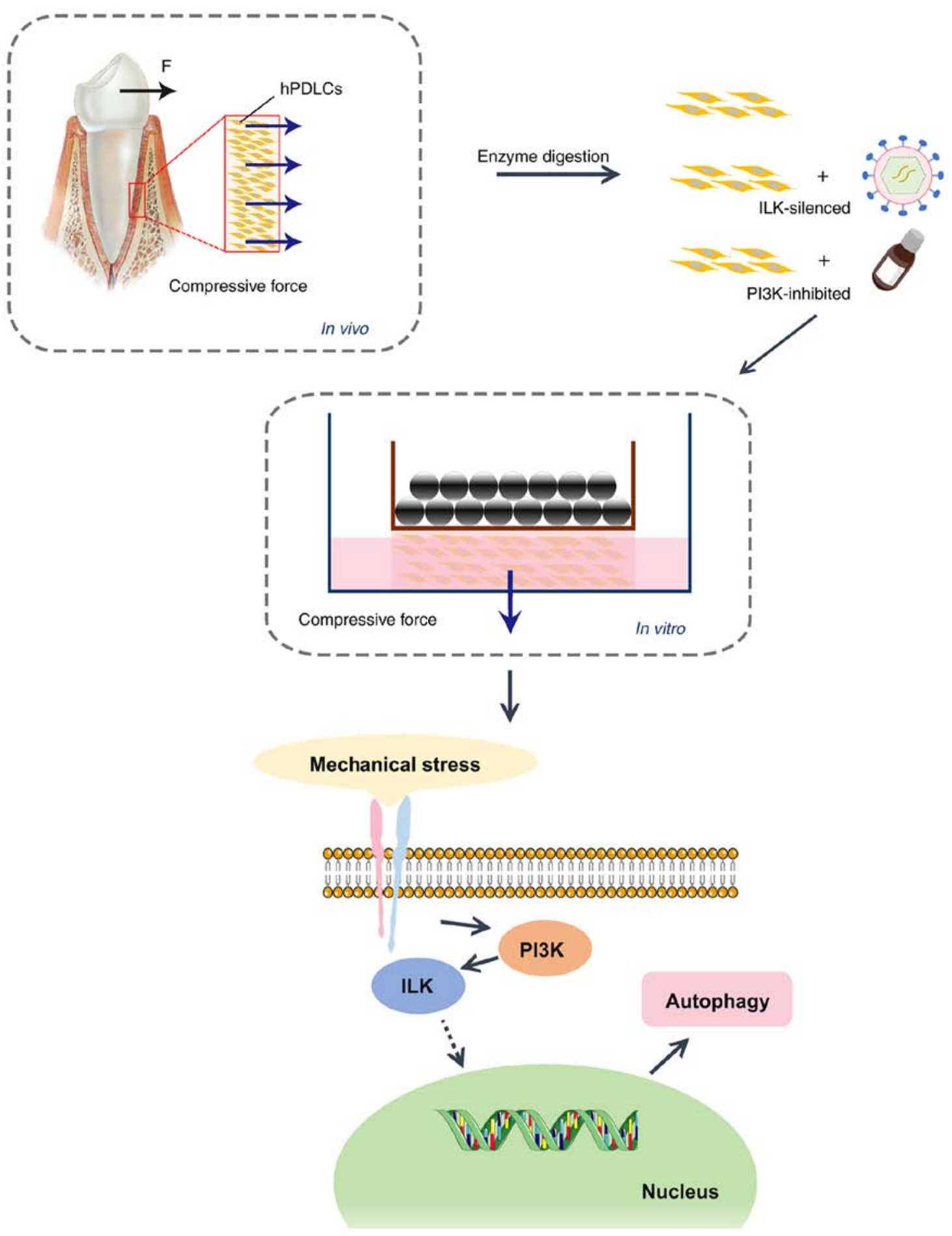

Figure 1. Schematic diagram of the method for exploring the synergistic effects of ILK and PI3K in the role of static compressive stress on autophagy of human periodontal ligament cells (hPDLCs). hPDLCs were obtained from the human periodontal ligament and divided into untreated, ILK silencing, and PI3K inhibitory groups. The compressive force of hPDLCs was simulated by applying gravity on the collagen-alginate hydrogel in vitro. The effects of mechanical stress on hPDLC autophagy and the potential modulatory mechanisms were then demonstrated by a series of corresponding assays. ILK, integrin-linked kinase; PI3K, phosphatidylinositol 3 kinase.

Transduction of ILK short hairpin (shRNA) lentiviral vectors. Two shRNAs targeting the human ILK mRNA (target sequence of ILK siRNA1, 5'-GTGGTTGAGATGTTGATCATG-3') and one negative control shRNA (target sequence of ILK siRNA2, 5'-TTC TCCGAACGTGTCACGT-3') were designed and synthesized by Shanghai GenePharma Co., Ltd. The hPDLCs were seeded in 6-well plates at a density of $1.2 \times 10^{5}$ cells/well. Lentiviruses (multiplicity of infection, 50) were diluted into the culture medium (containing $1 \mu \mathrm{l} / \mathrm{ml}$ of Polybrene) at 50-60\% hPDLC confluency. The medium-containing lentiviruses were removed and replaced with a fresh medium following $48 \mathrm{~h}$ of incubation $\left(37^{\circ} \mathrm{C}\right)$. The transfected cells were seeded in hydrogels and incubated for $48 \mathrm{~h}$ $\left(37^{\circ} \mathrm{C}\right)$ and were finally collected for experiments.

PI3K specific-inhibitory assay. For the present study, stock solutions of LY294002 (a specific inhibitor of PI3K, Echelon) 
dissolved in dimethyl sulfoxide (DMSO, Sigma-Aldrich; Merck KGaA), were diluted and added to the culture medium. Based on the results of the CCK- 8 assay, the final concentration of LY294002 was determined as $50 \mathrm{mmol} / \mathrm{l}$. The control group was treated with the same amount of DMSO. After $72 \mathrm{~h}$, the cells were harvested for western blotting to verify the inhibitory effect of LY294002 on PI3K.

Uniform weight method to exert static stress on hPDLCs. A 3D printer (Objet Eden260VS Dental Advantage, Stratasys) was used to produce a series of pre-designed molds. Weighed to $3,5,7$ and $10 \mathrm{~g}$, the mold was loaded with different sizes and number of steel balls and was placed on the hydrogel with hPDLCs embedded, pressed for 5,15 and $30 \mathrm{~min}$, and $1 \mathrm{~h}$, and then removed. A schematic diagram of static stress loading is shown in Fig. 2B.

Immunofluorescence staining. After washing the compressed hydrogel with PBS, three pieces of hydrogel with a thickness of $1 \mathrm{~mm}$ and a size of $2 \times 2 \mathrm{~mm}$ were randomly cut using a surgical blade and fixed in $4 \%$ paraformaldehyde, for $15 \mathrm{~min}$. Fixed hydrogels were permeabilized in $0.1 \%$ Triton X-100 (Beijing Solarbio Science \& Technology Co., Ltd) for $20 \mathrm{~min}$ before being washed three times with PBS. The pieces were blocked in 5\% bull serum albumin (Wuhan Boster Biological Technology, Ltd.) for $30 \mathrm{~min}$ at room temperature and incubated overnight with a primary antibody against LC3 (EPR18709, 1:200; Abcam) at $4^{\circ} \mathrm{C}$. Then, the pieces were incubated with CY3-labeled anti-rat secondary antibodies (BA1035, 1:50; Wuhan Boster Biological Technology, Ltd.) at room temperature, for $2 \mathrm{~h}$. After washing with PBS, the nuclei were stained with 4-6-diamidino-2-phenylindole (DAPI) for $5 \mathrm{~min}$ and were evaluated under a confocal microscope (Olympus Corporation). ImageJ software (Version 1.48; National Institutes of Health) was used to analyze the images. Background corrections and contrast/brightness enhancement were performed identically for all images with the same experiment.

Reverse transcription-quantitative polymerase chain reaction. After washing the compressed hydrogel with PBS, type IV collagenase (Sigma-Aldrich) and alginate lyase (Sigma-Aldrich; Merck KGaA) were used to dissolve the hydrogel. Finally, a resuspended cell sample was obtained. Total RNA was extracted from hPDLCs using RNAzol reagents (Molecular Research Center) following the manufacturer's protocol. cDNA was synthesized using Evo $M-M L V$ RT Premix reverse transcriptase (Takara Bio, Inc.) (26). qPCR was performed using the SYBR-Green premix Pro Taq HS qPCR kit (Takara Bio, Inc.). Glyceraldehyde-3-phosphate dehydrogenase $(G A P D H)$ was used as an internal control. The sequences of the primers are as follows: ILK forward, 5'-CCTGGATCA CTCCACAGTCC-3' and reverse, 5'-ATGATCGTCCCCCTG GTTGA-3'; ATG-5 forward, 5'-AAAGATGTGCTTCGAGAT GTGT-3' and reverse, 5'-CACTTTGTCAGTTACCAACGT CA-3'; Beclin-1 (BECN1) forward, 5'-GGTGTCTCTCGC AGATTCATC-3' and reverse, 5'-TCAGTCTTCGGCTGA GGTTCT-3'; GAPDH forward, 5'-ACCCACTCCTCCACC TTTG-3' and reverse, 5'-CACCACCCTGTTGCTGTAG-3'. RT-qPCR was repeated on at least three independent RNA preparations. The mRNA expression value was calculated using the $2^{-\Delta \Delta \mathrm{Cq}}$ method $(\Delta \mathrm{Cq}=$ the mean cycle threshold $\mathrm{Cq}$ of the target gene - the mean Cq of GAPDH; $\Delta \Delta \mathrm{Cq}=\Delta \mathrm{Cq}$ of the experimental group - $\Delta \mathrm{Ct}$ of the control group) (27).

Western blot analysis. The abovementioned method was used to obtain cells for western blot analysis. Total cellular proteins were extracted by adding a RIPA lysis buffer (Beyotime Institute of Biotechnology) containing $1 \%(\mathrm{v} / \mathrm{v})$ phenylmethanesulfonylfluoride (Beyotime) on ice. Protein concentrations were determined with a BCA protein assay kit (Beyotime Institute of Biotechnology). Equal protein amounts $(20 \mu \mathrm{g})$ were separated by sodium dodecyl sulfate polyacrylamide gel electrophoresis (SDS-PAGE) on 12-15\% gels and were transferred to polyvinylidene difluoride (PVDF) membranes. The membranes were blocked in 5\% non-fat dry milk for $1 \mathrm{~h}$ at room temperature and incubated overnight with phospho-AKT (mAb no. 4060, Ser473; Cell Signaling Technology, Inc.; 1:1,000), AKT (mAb no. 4691, Cell Signaling Technology, Inc.; $1: 1,000)$ and GAPDH antibodies (1:5,000, bs-12257R, BIOSS), at $4^{\circ} \mathrm{C}$. The following day, the membranes were washed with Tris-buffered saline with 0.05\% Tween-20 (Wuhan Boster Biological Technology,Ltd.) and then incubated with rabbit IgG horseradish peroxidase (HRP)-linked secondary antibodies (BA1054, 1:5,000; Wuhan Boster Biological Technology, Ltd.), for $1 \mathrm{~h}$ at room temperature (28). Finally, the bands were visualized using the Omega Lum G gel imaging system (Aplegen). ImageJ software (Version 1.48; National Institutes of Health) was used for densitometric analysis.

Statistical analysis. GraphPad prism software (Version 8.0; GraphPad, Inc.) was used for statistical analysis. Values are expressed as mean \pm standard error of the mean (SEM). One-way analysis of variance (ANOVA) followed by Tukey's multiple comparisons test were used to analyse the statistical significance of differences. $\mathrm{P}<0.05$ was considered statistically significant.

\section{Results}

Establishment of a $3 D$ culture model of hPDLCs using collagen-alginate composite hydrogel. Cells reside in a 3D environment in vivo. To simulate the microenvironment of the hPDLCs in the PDL, a collagen-alginate composite hydrogel was used in the present study. The preparation of the hydrogel is shown in Fig. 2A. After the cells were labelled with fluorescent tags, they were embedded in the hydrogel and the morphology was observed. At $1 \mathrm{~h}$ after embedding, the cells had not spread, and appeared as round bright spots; after $24 \mathrm{~h}$, the cells spread out in a spindle, and after $48 \mathrm{~h}$, a significant increase was observed in the number of cells (Fig. 3A). In addition, CCK- 8 was used to detect the OD value to evaluate the proliferation of hPDLCs in the collagen-alginate hydrogel. As shown in Fig. 3B, the OD value increased gradually from $0-24 \mathrm{~h}$ and increased rapidly from $24-72 \mathrm{~h}$ (Fig. $3 \mathrm{~B}, \mathrm{P}<0.05$ ), indicating excellent proliferation activity of hPDLCs in the collagen-alginate hydrogel.

Minimum static compressive stress force value that can cause autophagy in hPDLCs. A schematic diagram of the uniform 
A
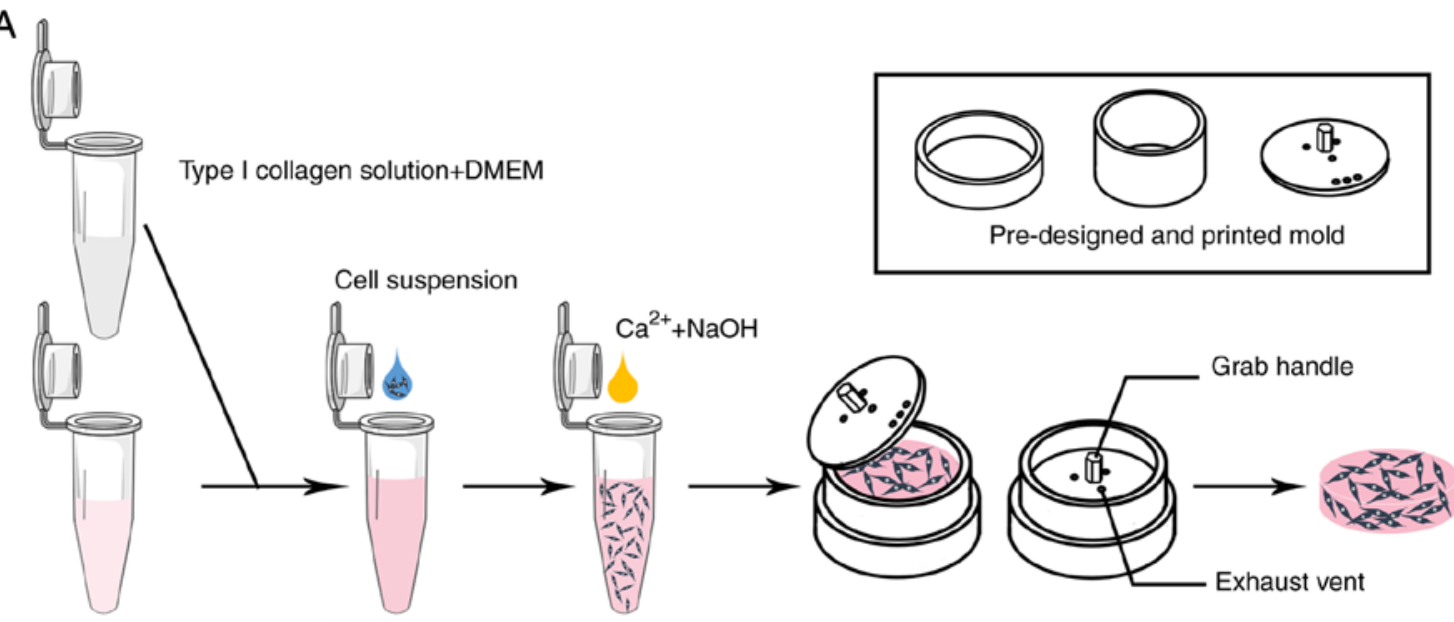

Alginate solution+DMEM

B

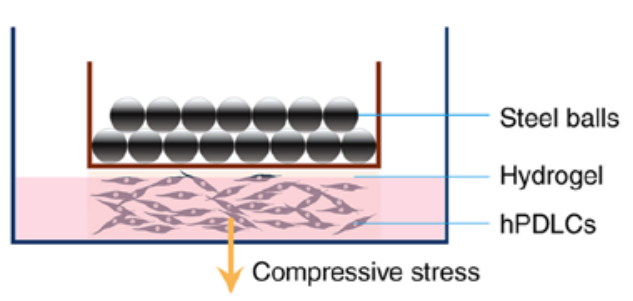

C

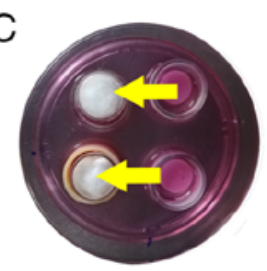

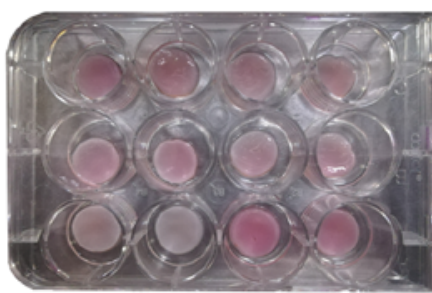

Figure 2. Three-dimensional (3D) culture of hPDLCs and the loading of compressive stress. (A) Schematic diagram of the preparation of the collagen-alginate complex hydrogel. We mixed collagen, alginate solution, and Dulbecco's modified Eagle's medium in certain proportions and added the cell suspension, calcium-crosslinked solution [composed of D-(+)-Glucono-1,5-lactone and $\mathrm{CaSO}_{4}$ ], and $\mathrm{NaOH}$ solution successively. (B) Schematic diagram of the uniform weight method. Cells were embedded in the hydrogel, and steel balls of certain weights were placed in the mould above it, which simulated a certain static compressive stress to hPDLCs using gravity. (C) Hydrogels under and after force loading. The yellow arrows show the load of a certain weight. hPDLCs, human periodontal ligament cells.

weight method and the hydrogel before and after compression is shown in Fig. 2B and C. Following compression, the hydrogel had flattened out. Based on a previous study, four compressive forces, including $1.5,2.5,3.5$ and $5 \mathrm{~g} / \mathrm{cm}^{2}$ were loaded to determine the lightest force that can induce the most active autophagic response. RT-qPCR was used to detect the expression of the autophagy-related genes, BECN1 and ATG-5, to reflect the level of autophagy. Compared with the 2.5 and $3.5 \mathrm{~g} / \mathrm{cm}^{2}$ groups, the expression levels of BECN1 and $A T G-5$ in the cells were decreased at $5 \mathrm{~g} / \mathrm{cm}^{2}$ loading for $15 \mathrm{~min}-1 \mathrm{~h}$, and the difference was significant (Fig. 3C, $\mathrm{P}<0.05)$. By contrast, the expression was elevated at 2.5 and $3.5 \mathrm{~g} / \mathrm{cm}^{2}$. Therefore, a lighter force that can cause an active autophagic response $\left(2.5 \mathrm{~g} / \mathrm{cm}^{2}\right)$ was selected as the workload in this study.

Effect of static compressive stress on cell autophagy in hPDLCs. The mRNA expression of BECN1 and ATG-5 in hPDLCs under a force of $2.5 \mathrm{~g} / \mathrm{cm}^{2}$ for different time points, is shown in Fig. 4A. With force loading, the mRNA levels of $B E C N 1$ and $A T G-5$ gradually increased, then decreased after 15 min (Fig. 4B and $\mathrm{C}, \mathrm{P}<0.001$ ) and returned to the initial level after $1 \mathrm{~h}$. The expression trend of $I L K$ exhibited a peak at 15 min (Fig. 4A, P<0.001), suggesting that ILK was involved in the process of static compressive stress-induced autophagy.

Immunofluorescence was performed to further detect the localization and expression of LC3 protein in hPDLCs. The red fluorescence diffused in the cytoplasm represents LC3I.
The red speckled fluorescence representing LC3II could be observed after $5 \mathrm{~min}$ of force-loading, indicating the appearance of autophagosomes (Fig. 4D). ImageJ software was used to analyze the average fluorescence intensity of both LC3I and LC3II, the ratio of which was considered a classic indicator of autophagy levels. The results were consistent with those of RT-qPCR (Fig. 4E). With the extension of the loading time, the ratio of LC3II/I gradually increased, then decreased at 30 min. Compared with the control group, the difference was significant $(\mathrm{P}<0.05)$.

ILK gene silencing and the role of ILK in the autophagy of hPDLCs induced by compressive stress. In this experiment, cells infected with green fluorescent protein (GFP)-tagged ILK shRNA lentivirus and empty vectors served as the experimental group (shILK) and negative control (shNC), respectively. Fluorescence expression of hPDLCs was evident in both the shILK and shNC groups, but not in the blank control group (Fig. 5A), indicating the high transfection rate of lentivirus vectors. RT-qPCR was used to verify the silencing of ILK. As shown in Fig. 5B, compared with the negative and blank controls, a significant decrease in ILK expression was observed in the experimental group (Fig. 5B, $\mathrm{P}<0.001$ ).

Furthermore, ILK-silenced hPDLCs were threedimensionally cultured and then subjected to static compressive stress. The results of RT-qPCR are shown in Fig. 5C-E. The expression trends of BECN1 and ATG-5 were consistent with those of the control group; they gradually increased to a 

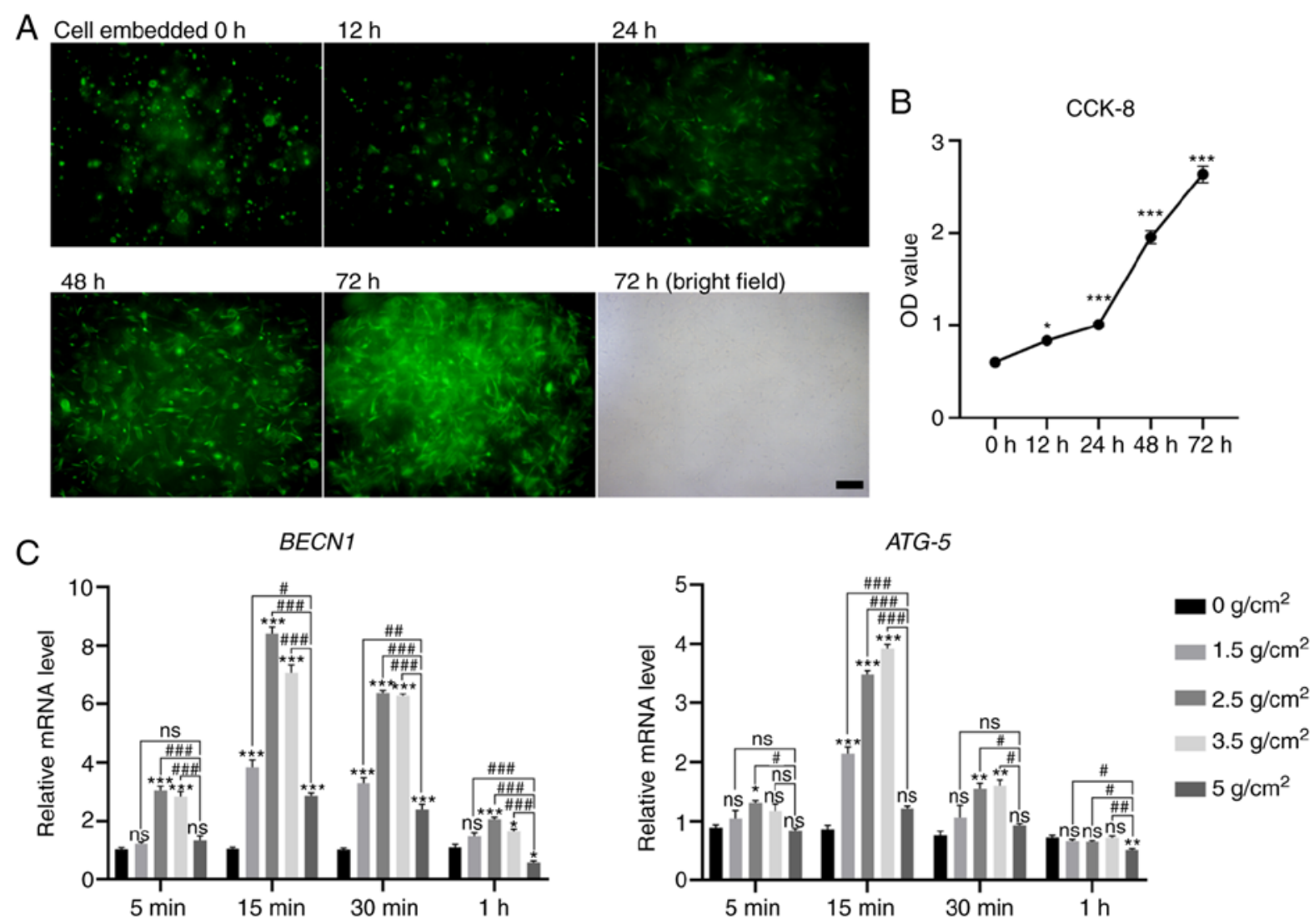

Figure 3. Growth and proliferation of three-dimensional cultured hPDLCs and the autophagy level with increasing intensity of the mechanical stimuli $(0,1.5$, 2.5, 3.5 and $5 \mathrm{~g} / \mathrm{cm}^{2}$ ) applied for different amounts of time $(5,15,30 \mathrm{~min}$ and $1 \mathrm{~h}$ ). (A) The spreading of hPDLCs (green fluorescence: GFP; scale bar, $200 \mu \mathrm{m}$ ). The cells appeared as rounded bright spots at $1 \mathrm{~h}$, spindles at $12 \mathrm{~h}$, and increased significantly after $24 \mathrm{~h}$. The morphology of hPDLCs embedded for $72 \mathrm{~h}$ in the bright field is also shown. (B) Optical density value. (C) Gene expression of Beclin-1 (BECNI) and ATG-5. Data are presented as mean \pm standard error of the mean. ${ }^{*} \mathrm{P}<0.05,{ }^{* *} \mathrm{P}<0.01$ and ${ }^{* * *} \mathrm{P}<0.001$, statistically significant differences from the $0 \mathrm{~g} / \mathrm{cm}^{2}$ group; ${ }^{*} \mathrm{P}<0.05,{ }^{\# \#} \mathrm{P}<0.01$ and ${ }^{\# \# \#} \mathrm{P}<0.001$, statistically significant differences from the $5 \mathrm{~g} / \mathrm{cm}^{2}$ group; ns, not significant ( $>0.05$ ). hPDLCs, human periodontal ligament cells; GFP, green fluorescent protein.

peak at $15 \mathrm{~min}$ and then decreased (Fig. 5D and $\mathrm{E} ; \mathrm{P}<0.05)$. However, the levels increased again at $1 \mathrm{~h}($ Fig. 5D and $\mathrm{E}$; $\mathrm{P}<0.05)$. The expression of $I L K$ rapidly recovered after force loading and the level then remained at a level similar to the level with shNC (Fig. 5C; $\mathrm{P}<0.001$ ). As shown in Fig. 5F and $\mathrm{G}$, autophagosomes were still present in ILK-silenced cells, although the average fluorescence intensity of LC3 was low, which increased with force-loading and decreased after 15 min (Fig. 5F and G, P<0.05). Additionally, a comparison of groups shNC and shILK at 0 min demonstrated that the expression of BECN1 and ATG-5 increased after the silencing of $I L K$, along with the ratio of LC3II/LC3I $(\mathrm{P}<0.05)$, reflecting an increase of the baseline level of autophagy (Fig. 5D, E and $\mathrm{G})$.

Specific inhibition of PI3K by LY294002 and the role of PI3K in the autophagy of hPDLCs induced by compressive stress. To investigate the role of $\mathrm{PI} 3 \mathrm{~K}$ in the induction of mechanical stress on autophagy, a specific inhibitor of PI3K, LY294002, was used in the present study. Following previous research, we set the drug concentration gradient of LY294002 and used the CCK-8 assay to detect the effects of drugs on cell proliferation and viability. For the present study, if the concentration was $\leq 50 \mathrm{mmol} / \mathrm{l}$, a negative effect of the drug on cell proliferation and viability was acceptable (Fig. 6A, P<0.01). Western blot analysis was used to detect the phosphorylation of PI3K downstream target proteins at the above-mentioned concentration. The results suggested that LY294002 significantly reduced the phosphorylation of AKT (Ser473) (Fig. 6B, P<0.01), which indicated that the kinase activity of PI3K was inhibited. The raw image files are shown in Figs. S2 and S3.

In the PI3K-inhibited cells, force loading did not upregulate $A T G-5$ expression (Fig. 6F, $\mathrm{P}>0.05$ ), while BECN1 expression increased slightly at $15 \mathrm{~min}$ (Fig. $6 \mathrm{E}, \mathrm{P}<0.05)$. Of note, it was found that the expression of ILK no longer increased with force loading, but remained unaltered (Fig. 6D, P>0.05). Similarly, the results of immunofluorescence revealed that the ratio of LC3II/I did not differ significantly between the groups (Fig. 6G and H, P>0.05).

\section{Discussion}

As part of the cell ecological niche, mechanical stress must be adapted to rapidly maintain both intracellular and extracellular homeostasis. Its effects on cells, tissues, and organs are very common in the body; for example, muscle development, bone remodeling, and the formation of skin calluses are all affected by external mechanical loads $(24,29)$. In the oral cavity, periodontal tissue is situated in a complex and active mechanical microenvironment. In particular, periodontal tissue regeneration during OTM has attracted a lot of attention. 
A

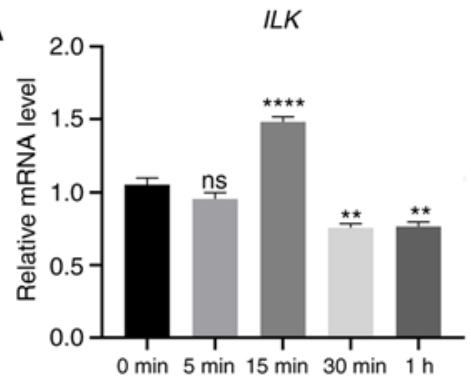

B

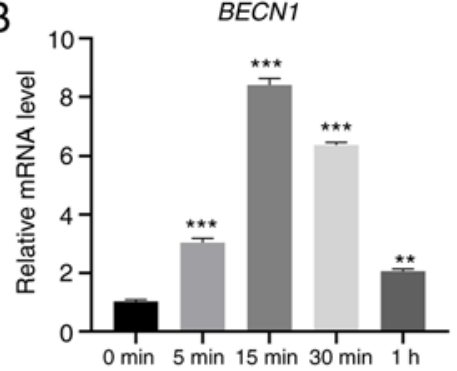

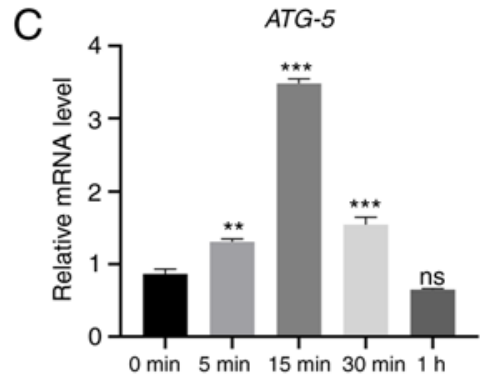

$1 \mathrm{~h}$

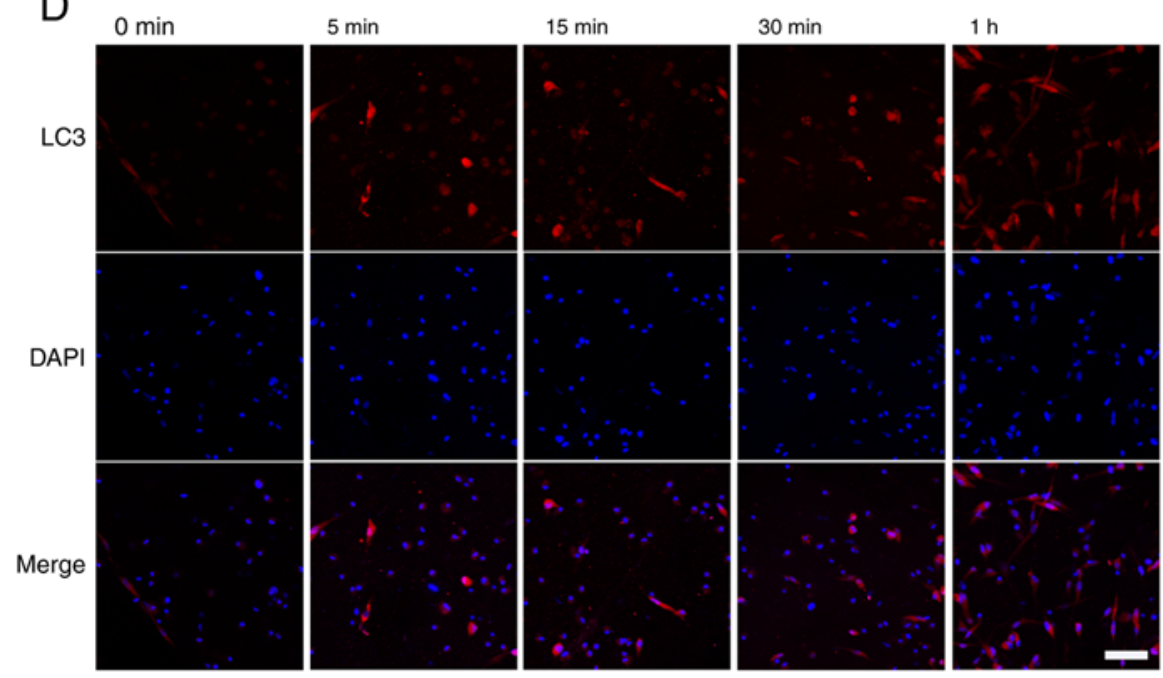

E

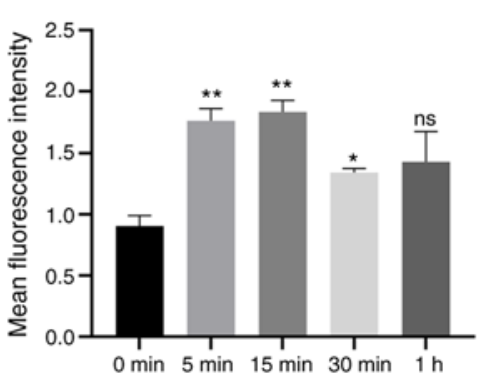

Figure 4. Effect of static compressive stress $\left(2.5 \mathrm{~g} / \mathrm{cm}^{2}\right)$ on gene expression of (A) ILK, (B) Beclin-1 (BECN1) and (C) ATG-5. The expression of LC3 in hPDLCs under compressive stress was observed by (D) immunofluorescence, red fluorescence: LC3; blue fluorescence: DAPI; scale bar, $200 \mu \mathrm{m}$. (E) The ratio of LC3II/LC3I. Data are presented as mean \pm standard error of the mean., ${ }^{*} \mathrm{P}<0.05,{ }^{* *} \mathrm{P}<0.01$ and ${ }^{* * *} \mathrm{P}<0.001$, statistically significant differences compared with the 0 min group; ns, not significant (P>0.05). hPDLCs, human periodontal ligament cells; ILK, integrin-linked kinase; DAPI, 4-6-diamidino-2-phenylindole.

At present, most models simulating orthodontic force reflect two-dimensional (2D) mechanical loading of cells, which cannot fully simulate the growth environment of cells in vivo (5). Therefore, the $3 \mathrm{D}$ culture model has attracted attention because it can accurately simulate the growth state of cells in the ECM (30). ILK, one of the targets of this study, is an important part of the focal adhesion complex. Previous findings indicated that in a 3D matrix, the adhesion of cells to the environment is special, such as the expression of adhesion molecules and changes in cell biological activity (31). This may lead to different responses of cells to the same mechanical stress, under 2D and 3D culture environments. Type I collagen is widely used in the research of hydrogel scaffolds, as a natural component of the ECM $(32,33)$. However, with the collagen hydrogel alone, it is difficult to load stable compressive stress due to its contractility (34). Thus, the collagen-alginate hydrogel model has been proposed for its excellent mechanical properties and permeability (35). In the current study, a collagen-alginate composite hydrogel loading model was constructed to simulate the $3 \mathrm{D}$ microenvironment of hPDLCs. The changes in cell morphology and the results of CCK-8 showed that the hPDLCs grew well in this hydrogel. This demonstrates that we have successfully constructed a 3D hydrogel model for hPDLCs.

Autophagy is a cellular function that maintains homeostasis and can be induced by mechanical stress $(11,36)$. The response of autophagy to mechanical stimuli has a range of force values. However, sustained stress can lead to excessive autophagy $(12,36,37)$. In this study, we designed an augmented device that simulates the compressive force exerted on hPDLCs, via hydrogels with a certain weight. According to previous studies, a range of pressure gradients were designed including $1.5,2.5,3.5$, and $5 \mathrm{~g} / \mathrm{cm}^{2}$. We found that the level of autophagy increased significantly under a compressive force of $2.5 \mathrm{~g} / \mathrm{cm}^{2}$, but only increased slightly or even decreased under $5 \mathrm{~g} / \mathrm{cm}^{2}$. This may be due to the force exceeding the limit of autophagy regulation, resulting in irreversible mechanical damage to cells. Thus, $2.5 \mathrm{~g} / \mathrm{cm}^{2}$ was selected as the workload in this study. With stress loading, the results of RT-qPCR revealed that the expression of BECN1 and ATG-5 increased and peaked at $15 \mathrm{~min}$. The fluorescence expression of LC3 showed the same change. This study confirmed that static compressive stress within a certain limit can indeed induce autophagy albeit this induction is rapid and short-lived, which is consistent with the results of King et al (11). This may be due to the smaller compressive stress and shorter action time allowing cells to adapt to this mechanical change rapidly, causing autophagy to return to the baseline level within $1 \mathrm{~h}$. In this process, indispensable mechanical signal transduction was considered.

ILK is a key structure of the ECM-integrin-cytoskeleton and plays an important role in cellular adaptation $(14,38)$. In the present study, the expression of $I L K$ was consistent with $B E C N 1$ and $A T G-5$, as predicted. To further explore the association between ILK, mechanical stress, and autophagy, ILK was silenced using lentivirus. Notably, ILK expression returned 
A

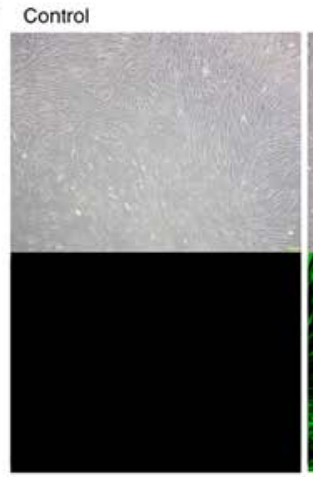

shNC

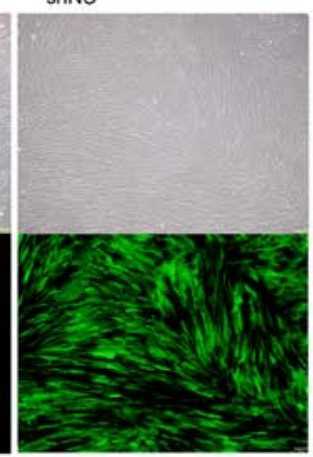

C

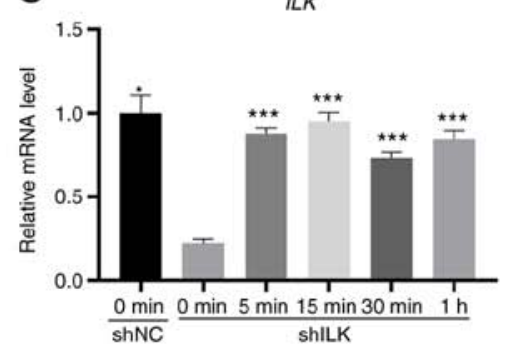

shiLK

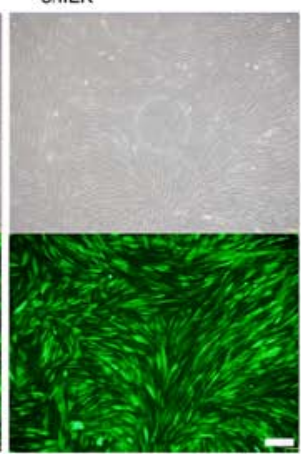

D

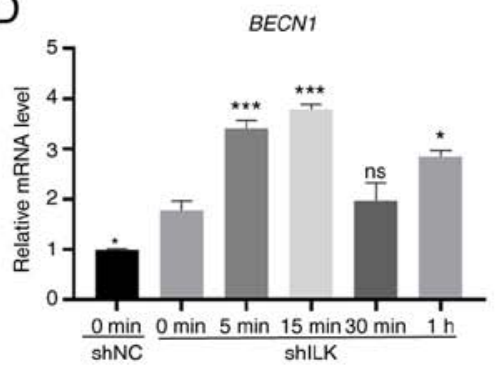

B

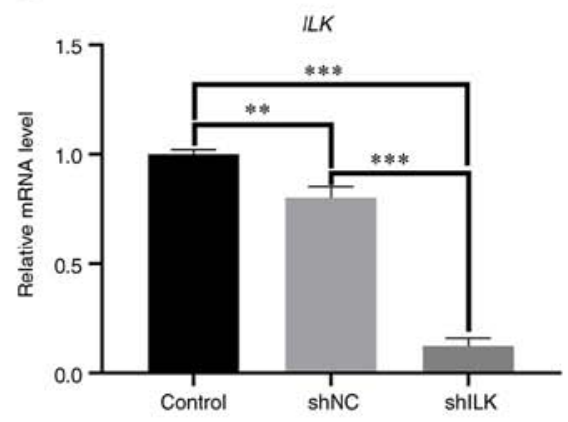

E

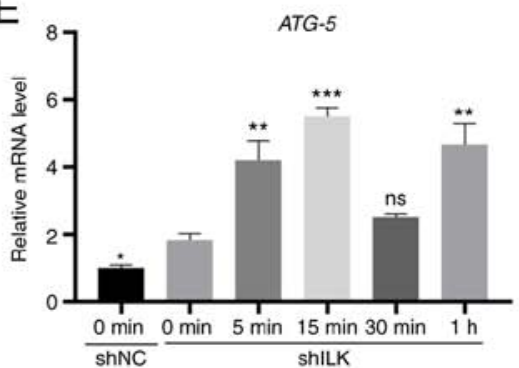

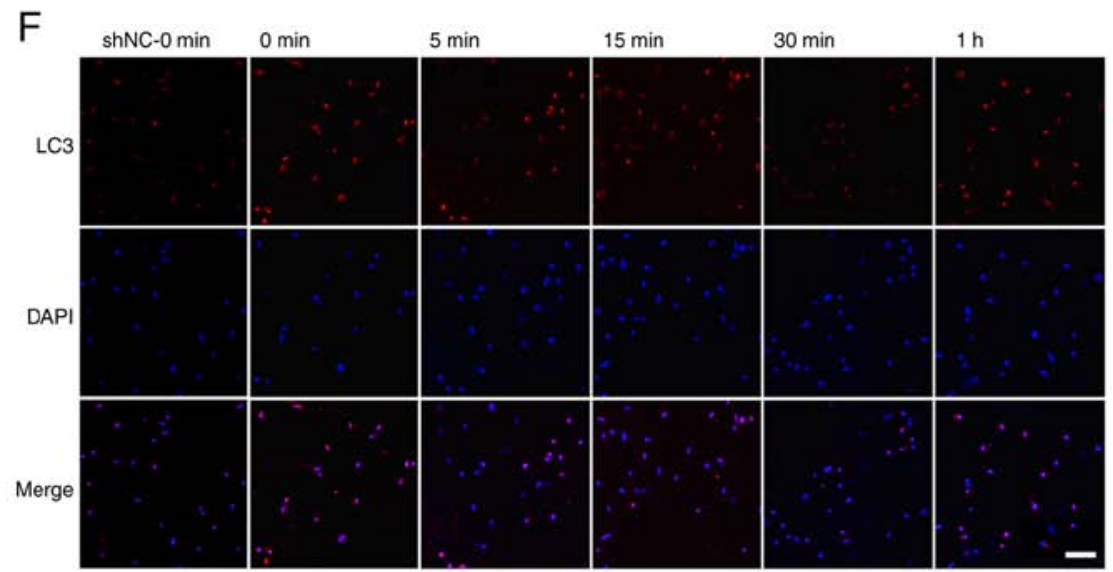

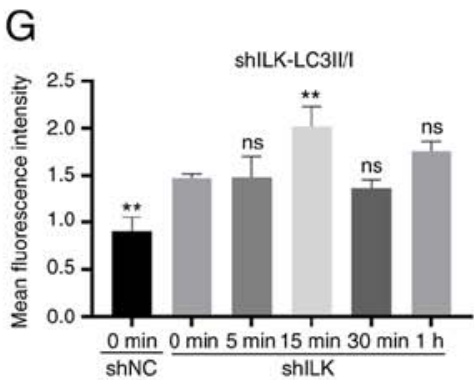

Figure 5. Loading static stress following the gene silencing of ILK. (A) Significant GFP expression was observed in both shNC and shILK groups (scale bar, $200 \mu \mathrm{m})$. (B) $I L K$ gene expression in shILK decreased significantly in comparison with shNC and control groups (P<0.001). (C) $I L K$ gene expression increased after stress loading for only 5 min $(\mathrm{P}<0.001)$. (D and $\mathrm{E})$ Beclin-1 (BECN1) and $A T G-5$ gene expression increased and decreased after 15 min $(\mathrm{P}<0.05)$. (F) Expression of LC3 (red fluorescence: LC3; blue fluorescence: DAPI; scale bar, $200 \mu \mathrm{m}$ ). (G) Ratio of LC3II/LC3I. Data are presented as mean \pm standard error of the mean. ${ }^{*} \mathrm{P}<0.05,{ }^{* * *} \mathrm{P}<0.01$ and ${ }^{* * *} \mathrm{P}<0.001$, statistically significant differences compared with the 0 min group (shILK); ns, not significant (P $>0.05$ ), ILK, integrin-linked kinase; GFP, green fluorescent protein; DAPI, 4-6-diamidino-2-phenylindole.

to the level before silencing after only 5 min of stress loading, despite $B E C N 1$ and $A T G-5$ expression trends being almost the same as those of the control group. However, it increased again at $1 \mathrm{~h}$. Whether a secondary activation of autophagy occurred at $1 \mathrm{~h}$ is unknown; thus, further studies are required to determine this using extended loading times. The results of immunofluorescence results revealed that the silencing of ILK could not block autophagy. However, the enhancement of $I L K$ expression may be an interference factor. Therefore, we concluded that mechanical stress could upregulate the expression of ILK and that ILK is not the only key molecule in autophagy. After deformation in the ECM due to cellular forces, integrin-induced actin filament rearrangement involves a variety of signaling proteins, including adhesion spot kinase, protein kinase $\mathrm{C}, \mathrm{PI} 3 \mathrm{~K}$, mitogen-activated kinases, and small Rho family guanosine triphosphates among others $(39,40)$, all of which may participate in the introduction of compressive stress signals. In addition, the autophagy level of shILK group went up at 0 min compared to the shNC group, indicating the double-sided function of ILK in autophagy. One possibility may be that the ILK functioned as a mechanical transduction molecule in the process of autophagy induced by mechanics (41). Conversely, it may be the upstream molecule of the AKT/mTOR pathway negatively regulating the autophagy (42), which may explain the increase in autophagy at $0 \mathrm{~min}$ in group shILK. Further investigation is required to determine the detailed mechanism.

As a key molecule downstream of the ECM-integrincytoskeleton signal transduction pathway, PI3K is involved in the regulation of various biological behaviors such as cell differentiation, proliferation, and autophagy (43). PI3K is closely related to the ILK function. ILK/PI3K downstream of mTOR 

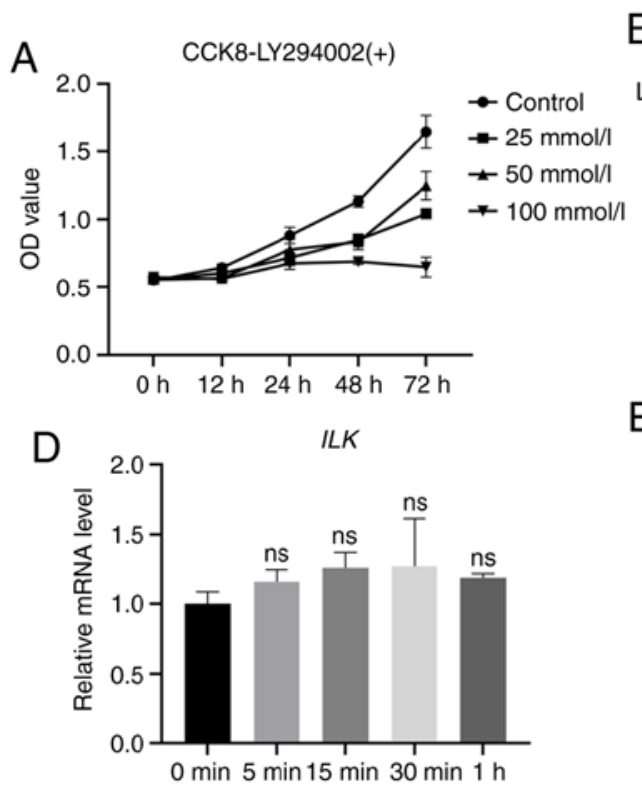

B

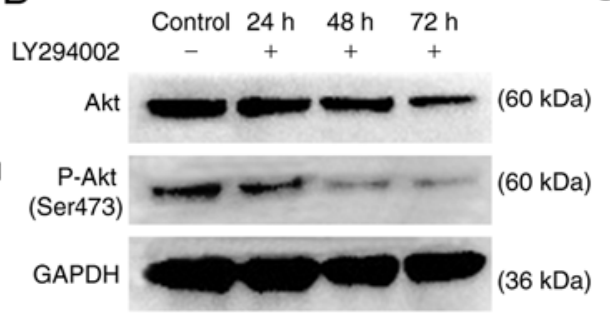

E

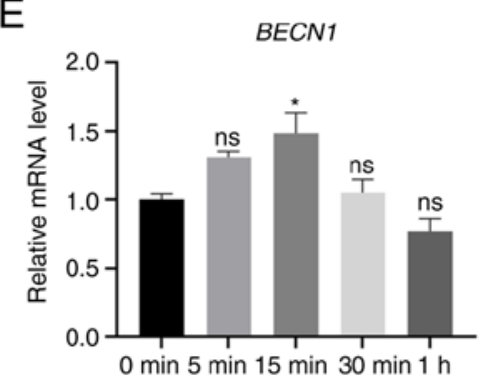

C

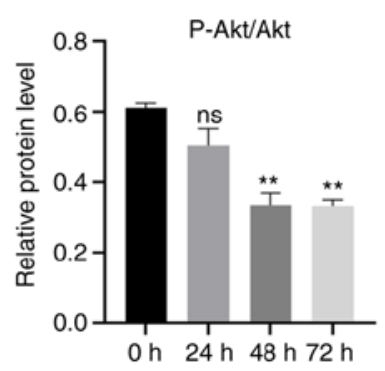

F

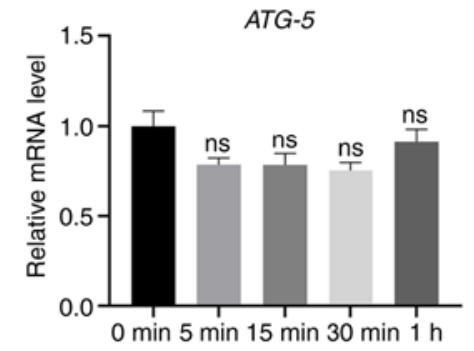

G
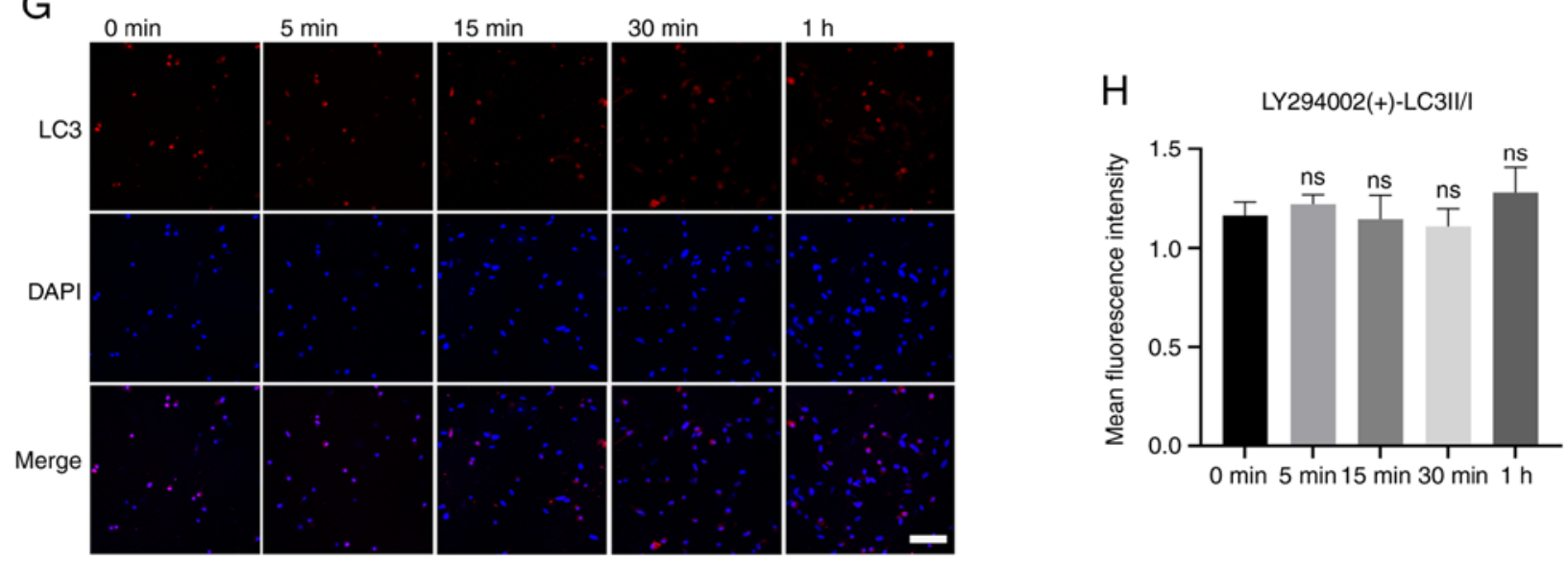

Figure 6. Loading static stress after PI3K inhibition. (A) Optical density value under different concentrations of drugs. (B) Protein expression level of AKT, P-AKT (Ser473) and GAPDH. (C) The ratio of P-AKT/total AKT level. (D) ILK gene expression. No significant change was found between groups (P>0.05). (E) Beclin-1 (BECN1) gene expression was slightly increased at $15 \mathrm{~min}(\mathrm{P}<0.05)$, while no significant change was observed in other groups $(\mathrm{P}>0.05)$. (F) ATG-5 gene expression remained unchanged between groups (P>0.05). (G) The expression of LC3 (red fluorescence: LC3; blue fluorescence: DAPI; scale bar, $200 \mu \mathrm{m})$. (H) The ratio of LC3II/LC3I. Data are presented as mean \pm standard error of the mean. ${ }^{*} \mathrm{P}<0.05$ and ${ }^{* * *} \mathrm{P}<0.01$, significant differences vs. the 0 min group; ns, not significant ( $\mathrm{P}>0.05$ ). PI3K, phosphatidylinositol 3 kinase; ILK, integrin-linked kinase; DAPI, 4-6-diamidino-2-phenylindole.

is the most characteristic negative regulator of autophagy (19). However, the mechanism of mechanically induced autophagy remains controversial. For instance, King et al (11) indicated that mechanical stress-induced autophagy is independent of the classic TOR signals or AMPK pathway. Other research found that the mTOR pathway could be activated rather than inhibited under mechanical tension in trabecular meshwork cells (44). To verify the role of ILK/PI3K in the regulation of autophagy induced by mechanical stress, LY294002 was used to inhibit the kinase activity of PI3K. Of note, after the inhibition of PI3K, the expression of $A T G-5$ no longer increased, but remained stable, although $B E C N 1$ expression was still slightly increased at $15 \mathrm{~min}$. This discrepancy may be due to the difference in the effective period of BECN1 and ATG-5 in autophagy. The PI3KIII complex, ATG-14, and ATG-6/BECN1 are all involved in the nucleation and assembly of the initial autophagosome, while ATG-5 plays a role in the subsequent extension of the autophagosome membrane (45). Therefore, we hypothesized that the inhibition of PI3K may have a greater impact on ATG-5 than on BECN1. Wang et al (46) found that fluid shear stress can induce autophagy in liver cancer cells through the PI3K-FAK-Rho GTPases pathway. Additionally, the use of PI3K inhibitor methyladenine (3-MA) significantly reduced the level of autophagy (46). Similarly, immunofluorescence results indicated that the autophagy level no longer increased with stress loading after PI3K-inhibition. This indicates that PI3K plays a crucial role in the process of mechanics-induced autophagy.

Previous findings have revealed the regulatory effect of PI3K on ILK function. For example, Delcommenne et al (20) found that the transient activation of insulin by ILK is dependent on PI3K, which may be achieved by phosphatidylinositol (3-5) triphosphate (PIP3), a product of PI3K. In addition, ILK can directly interact with the cytoplasmic domain of integrin and activate it in a PI3K-dependent manner (47). In the present study, the upregulating effect 
of mechanical stress on $I L K$ disappeared after PI3K was inhibited. Our results confirmed that mechanical stress can upregulate the expression of $I L K$ in a PI3K-dependent manner. This may provide evidence of the transduction mechanism of mechanical signals and the interaction with the role of ILK and PI3K in OTM.

However, the extraction of total protein of hPDLCs under 3D culture needs to be performed after the hydrogel is dissolved, and following protein degradation, which may affect the accuracy of the results. Therefore, the western blot assay of LC-3I/II and other autophagy-associated proteins were absent in this study. Ideal hydrogel that can be rapidly degraded and does not affect cells is required. In conclusion, the current findings confirmed that static compressive stress can induce autophagy within a certain range of force that is related to the ILK/PI3K signaling pathway. The inhibition of PI3K can invalidate the upregulation of ILK induced by mechanical stress. Further studies are required to clarify the downstream targeting pathway of mechanically induced autophagy and the mechanism involving mechanical stress, PI3K and ILK.

\section{Acknowledgements}

Not applicable.

\section{Funding}

The present study was supported by the Xi'an Science and Technology Project, China [no. 201805100YX8SF34(2)], the General project from the field of social Development, in Department of Science and Technology of Shaanxi Province, China (no. 2019SF-081), and by the National Natural Science Foundation, China (no. 8197032023).

\section{Availability of data and materials}

All data generated or analyzed during this study are included in this published article.

\section{Authors' contributions}

RZ, YW and YG conceived and designed the experiments. SW, XK and DZ drafted the manuscript and performed the experiments. SW and YW participated in data analysis and edited the manuscript. SZ, HS, BG and SM were involved in the discussion and interpretation of the results. $L N$ participated in data analysis and provided technical guidance. RZ and SW confirm the authenticity of all the raw data. All authors have read and approved the final manuscript.

\section{Ethics approval and consent to participate}

The present study was approved by the Ethics Committee of Stomatology Hospital of Xi'an Jiaotong University College of Medicine.

\section{Patient consent for publication}

Not applicable.

\section{Competing interests}

The authors declare that they have no competing interests.

\section{References}

1. Berry S, Javed F, Rossouw PE, Barmak AB, Kalogirou EM and Michelogiannakis D: Influence of thyroxine supplementation on orthodontically induced tooth movement and/or inflammatory root resorption: A systematic review. Orthod Craniofac Res 24: 206-213, 2020.

2. Jin Y, Li J, Wang YT, Ye R, Feng XX, Jing Z and Zhao Z: Functional role of mechanosensitive ion channel Piezol in human periodontal ligament cells. Angle Orthodontist 85: 87-94, 2015.

3. Kikuta J, Yamaguchi M, Shimizu M, Yoshino T and Kasai K: Notch signaling induces root resorption via RANKL and IL-6 from hPDL cells. J Dental Res 94: 140-147, 2015.

4. Chang ML, Lin H, Fu HD, Wang BK, Han GL and Fan MW: MicroRNA-195-5p regulates osteogenic differentiation of periodontal ligament cells under mechanical loading. J Cell Physiology 232: 3762-3774, 2017.

5. Duval K, Grover H, Han LH, Mou Y, Pegoraro AF, Fredberg J and Chen Z: Modeling physiological events in 2D vs. 3D cell culture. Physiology (Bethesda) 32: 266-277, 2017.

6. Zhao Y, Wang C, Li S, Song H, Wei F, Pan K, Zhu K, Yang P, Tu Q and Chen J: Expression of Osterix in mechanical stress-induced osteogenic differentiation of periodontal ligament cells in vitro. Eur J Oral Sci 116: 199-206, 2008.

7. Chen JL, Zhang W, Backman LJ, Kelk P and Danielson P: Mechanical stress potentiates the differentiation of periodontal ligament stem cells into keratocytes. Brit J Ophthalmol 102: 562-569, 2018.

8. Banerjee A and Bandopadhyay R: Autophagy: Nobel prize in physiology or medicine' 16 to the intra-cellular suicidal process. Natl Acad Sci Lett 40: 461-465, 2017.

9. Klionsky DJ and Emr SD: Autophagy as a regulated pathway of cellular degradation. Science 290: 1717-1721, 2000.

10. Ott C, König J, Höhn A, Jung T and Grune T: Macroautophagy is impaired in old murine brain tissue as well as in senescent human fibroblasts. Redox Biol 10: 266-273, 2016.

11. King JS, Veltman DM and Insall RH: The induction of autophagy by mechanical stress. Autophagy 7: 1490-1499, 2011.

12. Ma KG, Shao ZW, Yang SH, Wang J, Wang BC, Xiong LM, Wu Q and Chen SF: Autophagy is activated in compression-induced cell degeneration and is mediated by reactive oxygen species in nucleus pulposus cells exposed to compression. Osteoarthr Cartilage 21: 2030-2038, 2013.

13. Iskratsch T, Wolfenson $\mathrm{H}$ and Sheetz MP: Appreciating force and shape - the rise of mechanotransduction in cell biology. Nat Rev Mol Cell Bio 15: 825-833, 2014.

14. Kechagia JZ, Ivaska J and Roca-Cusachs P: Integrins as biomechanical sensors of the microenvironment. Nat Rev Mol Cell Bio 20: 457-473, 2019.

15. Zheng CC, Hu HF, Hong P, Zhang QH, Xu WW, He QY and Li B: Significance of integrin-linked kinase (ILK) in tumorigenesis and its potential implication as a biomarker and therapeutic target for human cancer. Am J Cancer Res 9: 186-197, 2019.

16. Zheng QM, Chen XY, Bao QF, Yu J and Chen LH: ILK enhances migration and invasion abilities of human endometrial stromal cells by facilitating the epithelial-mesenchymal transition. Gynecol Endocrinol 34: 1091-1096, 2018.

17. Zhu XY, Liu N, Liu W, Song SW and Guo KJ: Silencing of the integrin-linked kinase gene suppresses the proliferation, migration and invasion of pancreatic cancer cells (Panc-1). Genet Mol Biol 35: 538-544, 2012.

18. Sakai T, Li S, Docheva D, Grashoff C, Sakai K, Kostka G, Braun A, Pfeifer A, Yurchenco PD and Fässler R: Integrin-linked kinase (ILK) is required for polarizing the epiblast, cell adhesion, and controlling actin accumulation. Genes Dev 17: 926-940, 2003.

19. Jung $\mathrm{CH}$, Ro SH, Cao J, Otto NM and Kim DH: mTOR regulation of autophagy. FEBS Lett 584: 1287-1295, 2010.

20. Delcommenne M, Tan C, Gray V, Rue L, Woodgett J and Dedhar S: Phosphoinositide-3-OH kinase-dependent regulation of glycogen synthase kinase 3 and protein kinase B/AKT by the integrin-linked kinase. Proc Natl Acad Sci USA 95: 11211-11216, 1998. 
21. Sosa P, Alcalde-Estevez E, Plaza P, Troyano N, Alonso C, Martínez-Arias L, Evelem de Melo Aroeira A, RodriguezPuyol D, Olmos G, López-Ongil S and Ruíz-Torres MP: Hyperphosphatemia promotes senescence of myoblasts by impairing autophagy through Ilk overexpression, a possible mechanism involved in sarcopenia. Aging Dis 9: 769-784, 2018.

22. Wan WT, He C, Du CY, Wang YJ, Wu SY, Wang TR and Zou R: Effect of ILK on small-molecule metabolism of human periodontal ligament fibroblasts with mechanical stretching. J Periodontal Res 55: 229-237, 2020.

23. Wang Y, Du C, Wan W, He C, Wu S, Wang T, Wang F and Zou R: shRNA knockdown of integrin-linked kinase on hPDLCs migration, proliferation, and apoptosis under cyclic tensile stress. Oral Dis 26: 1747-1754, 2020.

24. Li M, Zhang $\mathrm{C}$ and Yang Y: Effects of mechanical forces on osteogenesis and osteoclastogenesis in human periodontal ligament fibroblasts: A systematic review of in vitro studies. Bone Joint Res 8: 19-31, 2019.

25. Yang J, Zhou J, Cui B and Yu T: Evaluation of hypoxia on the expression of miR-646/IGF-1 signaling in human periodontal ligament cells (hPDLCs). Med Sci Monit 24: 5282-5291, 2018.

26. Brazvan B, Farahzadi R, Mohammadi SM, Saheb SM, Shanehbandi D, Schmied L, Soleimani Rad J, Darabi M and Nozad Charoudeh H: Key immune cell cytokines affects the telomere activity of cord blood cells in vitro. Adv Pharm Bull 6 : 153-161, 2016.

27. Livak KJ and Schmittgen TD: Analysis of relative gene expression data using real-time quantitative PCR and the 2(-Delta Delta C(T)) method. Methods 25: 402-408, 2001

28. Farahzadi R, Fathi E and Vietor I: Mesenchymal stem cells could be considered as a candidate for further studies in cell-based therapy of Alzheimer's disease via targeting the signaling pathways. ACS Chem Neurosci 11: 1424-1435, 2020

29. Moraes C, Sun Y and Simmons CA: (Micro)managing the mechanical microenvironment. Integr Biol (Camb) 3: 959-971, 2011.

30. Wozniak MA, Modzelewska K, Kwong L and Keely PJ: Focal adhesion regulation of cell behavior. Biochim Biophys Acta 1692: 103-119, 2004

31. Cukierman E, Pankov R, Stevens DR and Yamada KM: Taking cell-matrix adhesions to the third dimension. Science 294: 1708-1712, 2001

32. Oh SA, Lee HY, Lee JH, Kim TH, Jang JH, Kim HW and Wall I: Collagen three-dimensional hydrogel matrix carrying basic fibroblast growth factor for the cultivation of mesenchymal stem cells and osteogenic differentiation. Tissue Eng Part A 18 $1087-1100,2012$

33. Rajan N, Habermehl J, Cote MF, Doillon CJ and Mantovani D Preparation of ready-to-use, storable and reconstituted type I collagen from rat tail tendon for tissue engineering applications. Nat Protoc 1: 2753-2758, 2006.

34. Yuan T, Zhang L, Feng L, Fan H and Zhang X: Chondrogenic differentiation and immunological properties of mesenchymal stem cells in collagen type I hydrogel. Biotechnol Prog 26 $1749-1758,2010$
35. Branco da Cunha C, Klumpers DD, Li WA, Koshy ST, Weaver JC, Chaudhuri O, Granja PL and Mooney DJ: Influence of the stiffness of three-dimensional alginate/collagen-I interpenetrating networks on fibroblast biology. Biomaterials 35: 8927-8936, 2014.

36. Li D, Lu Z, Xu Z, Ji J, Zheng Z, Lin S and Yan T: Spironolactone promotes autophagy via inhibiting PI3K/AKT/mTOR signalling pathway and reduce adhesive capacity damage in podocytes under mechanical stress. Biosci Rep 36: e00355, 2016.

37. Xu HG, Yu YF, Zheng Q, Zhang W, Wang CD, Zhao XY, Tong WX, Wang H, Liu P and Zhang XL: Autophagy protects end plate chondrocytes from intermittent cyclic mechanical tension induced calcification. Bone 66: 232-239, 2014.

38. Ghatak S, Morgner J and Wickstrom SA: ILK: A pseudokinase with a unique function in the integrin-actin linkage. Biochem Soc Trans 41: 995-1001, 2013

39. Vautrin-Glabik A, Botia B, Kischel P, Ouadid-Ahidouch H and Rodat-Despoix L: $\mathrm{IP}_{3} \mathrm{R} 3$ silencing induced actin cytoskeletal reorganization through ARHGAP18/RhoA/mDia1/FAK pathway in breast cancer cell lines. Biochim Biophys Acta Mol Cell Res 1865: 945-958, 2018.

40. Memmel S, Sisario D, Zoller C, Fiedler V, Katzer A, Heiden R, Becker N, Eing L, Ferreira FLR, Zimmermann H, et al: Migration pattern, actin cytoskeleton organization and response to PI3K-, mTOR-, and Hsp90-inhibition of glioblastoma cells with different invasive capacities. Oncotarget 8: 45298-45310, 2017.

41. Boppart MD and Mahmassani ZS: Integrin signaling: Linking mechanical stimulation to skeletal muscle hypertrophy. Am J Physiol Cell Physiol 317: C629-C641, 2019.

42. Mousavizadeh R, Hojabrpour P, Eltit F, McDonald PC, Dedhar S, McCormack RG, Duronio V, Jafarnejad SM and Scott A: $\beta 1$ integrin, ILK and mTOR regulate collagen synthesis in mechanically loaded tendon cells. Sci Rep 10: 12644, 2020.

43. Fruman DA, Chiu H, Hopkins BD, Bagrodia S, Cantley LC and Abraham RT: The PI3K pathway in human disease. Cell 170: 605-635, 2017.

44. Porter KM, Jeyabalan N and Liton PB: MTOR-independent induction of autophagy in trabecular meshwork cells subjected to biaxial stretch. Biochim Biophys Acta 1843: 1054-1062, 2014.

45. Nishimura T and Tooze SA: Emerging roles of ATG proteins and membrane lipids in autophagosome formation. Cell Discov 6: 32, 2020.

46. Wang X, Zhang Y, Feng T, Su G, He J, Gao W, Shen Y and Liu X: Fluid shear stress promotes autophagy in hepatocellular carcinoma cells. Int J Biol Sci 14: 1277-1290, 2018.

47. Dedhar S: Cell-substrate interactions and signaling through ILK. Curr Opin Cell Biol 12: 250-256, 2000.

This work is licensed under a Creative Commons Attribution-NonCommercial-NoDerivatives 4.0 International (CC BY-NC-ND 4.0) License. 